\title{
PERSISTENCIA DE ANTICUERPOS MATERNALES CONTRA EL VIRUS DE LA PESTE PORCINA CLÁSICA EN LECHONES NACIDOS DE MARRANAS EN GRANJAS CON DIFERENTES ESTRATEGIAS DE VACUNACIÓN
}

\author{
Maternal Antibody Persistence against the Classical Swine Fever Virus in \\ Piglets Born from Vaccinated Sows in Farms With Different Vaccination \\ STRATEgies
}
Katherine Portilla J. ${ }^{1}$, Alberto Manchego S. ${ }^{1,2}$, Hermelinda Rivera G. ${ }^{1}$, Mariluz Araínga R. ${ }^{1}$ y Marcy Ramírez V. ${ }^{1}$

\section{Resumen}

El objetivo del estudio fue evaluar la persistencia de los anticuerpos pasivos contra el virus de la Peste Porcina Clásica (vPPC) en lechones de dos granjas tecnificadas (A y B) con distintas estrategias de vacunación contra el vPPC. En la granja A, las marranas fueron vacunadas a los 90 días de gestación y en B a los 18 a 21 días post-parto. Se colectó muestras de sangre de lechones de ambas granjas durante la primera $(n=15)$, tercera $(n=15)$, quinta $(n=15)$ y séptima $(n=15)$ semana de edad, así como de 15 marranas por granja para la detección de los anticuerpos mediante la prueba de ELISA indirecta. Todos los lechones presentaron anticuerpos pasivos en la primera semana de edad, persistiendo en la mayoría de los lechones hasta la séptima semana de edad. Hubo diferencia significativa $(\mathrm{p}<0.05)$ en los niveles de anticuerpos pasivos entre los lechones de las dos granjas en la primera y tercera semana de edad. Asimismo, se observó una mayor variabilidad en los niveles de anticuerpos en lechones y en marranas de la granja A. Los resultados sugieren que los niveles y la persistencia de los anticuerpos pasivos contra el vPPC se afectan por la estrategia de vacunación contra la PPC.

Palabras clave: virus de la Peste Porcina Clásica, vPPC, anticuerpos maternales, lechones, marranas, vacunación, granjas porcinas

\section{Abstract}

In the study was evaluated the persistence of maternal antibodies levels against the Classical Swine Fever virus (CSFV) in piglets born from vaccinated sows from two farms (A and B) with different vaccination strategies against CSFV. In farm A sows were vaccinated at 90 days of gestation and in farm B at $18-21$ days postpartum. Serum samples were collected from piglets of both farms, at first $(n=15)$, third $(n=15)$, fifth $(n=15)$

1 Laboratorio de Microbiología y Parasitología Veterinaria, Facultad de Medicina Veterinaria, Universidad Nacional Mayor de San Marcos, Lima

2 E-mail: amanchegos@unmsm.edu.pe 
and seventh ( $\mathrm{n}=15)$ weeks of age, and from 15 sows from each farm A for detection of antibodies against CSFV by the indirect ELISA test. All piglets had maternal antibodies against CSFV at first week of age, persisting in most of them to the seventh week of age. Significant differences between farms were found $(\mathrm{p}<0.05)$ on levels of maternal antibodies in piglets at first and third week of age. Also, higher variability on antibody levels was observed $\mathrm{n}$ piglets and sows in farm A. The results suggest that the level and persistence of the maternal antibodies in piglets depend of vaccination strategies against PPC virus.

Key words: Classical Swine Fever Virus, CSFV, maternal antibodies, piglet, sow, vaccination, pig farms

\section{INTRODUCCIÓN}

La Peste Porcina Clásica (PPC) es una enfermedad multisistémica, contagiosa y a menudo fatal, que afecta a los cerdos domésticos y silvestres en forma aguda, crónica y subclínica. La Oficina Internacional de Epizootias (OIE, 2004) la considera una enfermedad de notificación obligatoria por ser muy contagiosa y de impacto económico (Moennig et al., 2003). La PPC ha sido erradicada de países como Estados Unidos, Inglaterra, Holanda, Australia y Chile entre otros, pero está presente en la mayoría de los países de América Latina (van Oirschot, 2003).

La PPC es producida por el virus de la peste porcina clásica (vPPC), un miembro del género pestivirus de la familia Flaviviridae (Fauquet et al., 2005). El virus posee un solo serotipo con cepas de baja, moderada y alta virulencia que induce la PPC de forma subclínica, moderada y aguda, respectivamente. La marrana gestante, al infectarse presenta un conjunto de fallas reproductivas como infertilidad, abortos, malformaciones congénitas, y nacimiento de lechones débiles o muertos (Choi y Chae, 2003). Asimismo, si la infección ocurre en el primer tercio de gestación con cepas de baja virulencia, los lechones pueden nacer inmunotolerantes y portadores del virus, conocidos como animales persistentemente infectados (van Oirschot y Terpstra, 1977), pudiendo ser clínicamente normales y sobrevivir por varios meses (Moennig, 1999; Moennig et al., 2003).
Animales inmunosuprimidos de cualquier edad desarrollan infecciones subclínicas cuando son infectados con virus de baja y moderada virulencia. Tanto los animales persistentemente infectados y los infectados subclínicamente son los diseminadores del virus dentro de los sistemas de producción porcina (Camacho, 2005). En el Perú, la forma aguda de la enfermedad se observa mayormente en crianzas de porcinos sin adecuada tecnología, mientras que la forma subclínica o atípica puede presentarse en las crianzas tecnificadas (Rivera, 1994; Angeles et al., 1999).

La prevención y control de la enfermedad está basada en la inmunización mediante el uso de vacunas a base a virus vivo modificado, ya sea lapinizada o preparada en cultivo celular, utilizándose como virus semilla, en ambos tipos de vacuna, a la cepa China del vPPC (van Oirschot, 1999, 2003). Estas vacunas inducen una buena respuesta inmunitaria celular y humoral (Moennig, 2000) $\mathrm{u}$ otras cepas. Estas vacunas inducen una buena respuesta inmunitaria celular y humoral (Moennig, 2000) como ha sido demostrado en países como EEUU, Canadá y Australia, entre otros, que lograron erradicar la enfermedad utilizando un programa basado en la vacunación sistemática de la población porcina.

Las estrategias de vacunación que se utilizan en granjas tecnificadas del país se basan en la vacunación de las marranas 90 días antes del parto o 15 días antes del servicio; sin embargo, las granjas porcinas del país 
Cuadro 1. Frecuencia numérica de anticuerpos pasivos contra el virus de Peste Porcina Clásica en lechones de dos granjas de la zona de Lima según edad

\begin{tabular}{ccccccccc}
\hline \multirow{2}{*}{$\begin{array}{l}\text { Edad } \\
\text { (semanas })\end{array}$} & \multicolumn{4}{c}{ Granja A } & \multicolumn{5}{c}{ Granja B } \\
\cline { 2 - 9 } & Pos $^{1}$ & Neg & Sosp & Total & Pos & Neg & Sosp & Total \\
\hline 1 & 15 & - & - & 15 & 15 & - & - & 15 \\
3 & 13 & 1 & 1 & 15 & 15 & - & - & 15 \\
5 & 14 & 1 & - & 15 & 14 & - & 1 & 15 \\
7 & 15 & - & - & 15 & 10 & 3 & 2 & 15 \\
\hline Total & 57 & 2 & 1 & 60 & 54 & 3 & 3 & 60 \\
\hline
\end{tabular}

${ }^{1}$ Pos = Positivo; Neg = Negativo; Sosp = Sospechoso

Cuadro 2. Niveles de anticuerpos pasivos contra el virus de Peste Porcina Clásica, expresados en porcentajes de inhibición y coeficiente de variación $(\mathrm{CV})$, en lechones de dos granjas de la zona de Lima según edad

\begin{tabular}{cccccc}
\hline \multirow{2}{*}{$\begin{array}{c}\text { Edad } \\
\text { Semana })\end{array}$} & \multirow{2}{*}{$\begin{array}{c}\text { N. }^{\mathrm{d}} \text { de } \\
\text { muestras }\end{array}$} & \multicolumn{2}{c}{ Granja A } & \multicolumn{2}{c}{ Granja B } \\
\cline { 3 - 6 } & 15 & $117.2^{\mathrm{a}}$ & 20.7 & $98.9^{\mathrm{b}}$ & 9.5 \\
\hline 1 & 15 & $77.9^{\mathrm{a}}$ & 42.0 & $98.2^{\mathrm{b}}$ & 9.9 \\
3 & 15 & 75.3 & 30.2 & 86.5 & 22.0 \\
5 & 15 & 73.3 & 26.8 & 61.1 & 41.3 \\
7 & & & & & \\
\hline
\end{tabular}

a,b Superíndices diferentes dentro de filas indican diferencia significativa $(p<0.05)$

${ }^{1}$ Coeficiente de variación

no están libres de la enfermedad debido a diversos factores, incluyendo la escasa información disponible sobre la epidemiología de la PPC en el país, la respuesta inmunitaria del animal vacunado, el tiempo de persistencia de los anticuerpos pasivos, y la presencia de animales portadores (Camargo et al., 2002).

En este contexto, el presente estudio tuvo como objetivo determinar la persistencia de anticuerpos pasivos en lechones procedentes de dos granjas porcinas tecnificadas que utilizan distintas estrategias de vacunación contra la PPC.

\section{Materiales y Métodos}

Se trabajó en dos granjas porcinas tecnificadas del valle de Lima. La primera, con una población promedio de 1200 marranas y 6000 animales para engorde donde el esquema de vacunación contra la PPC fue de 90 días antes del parto (granja A), y la otra, con 550 marranas y 2500 animales para 


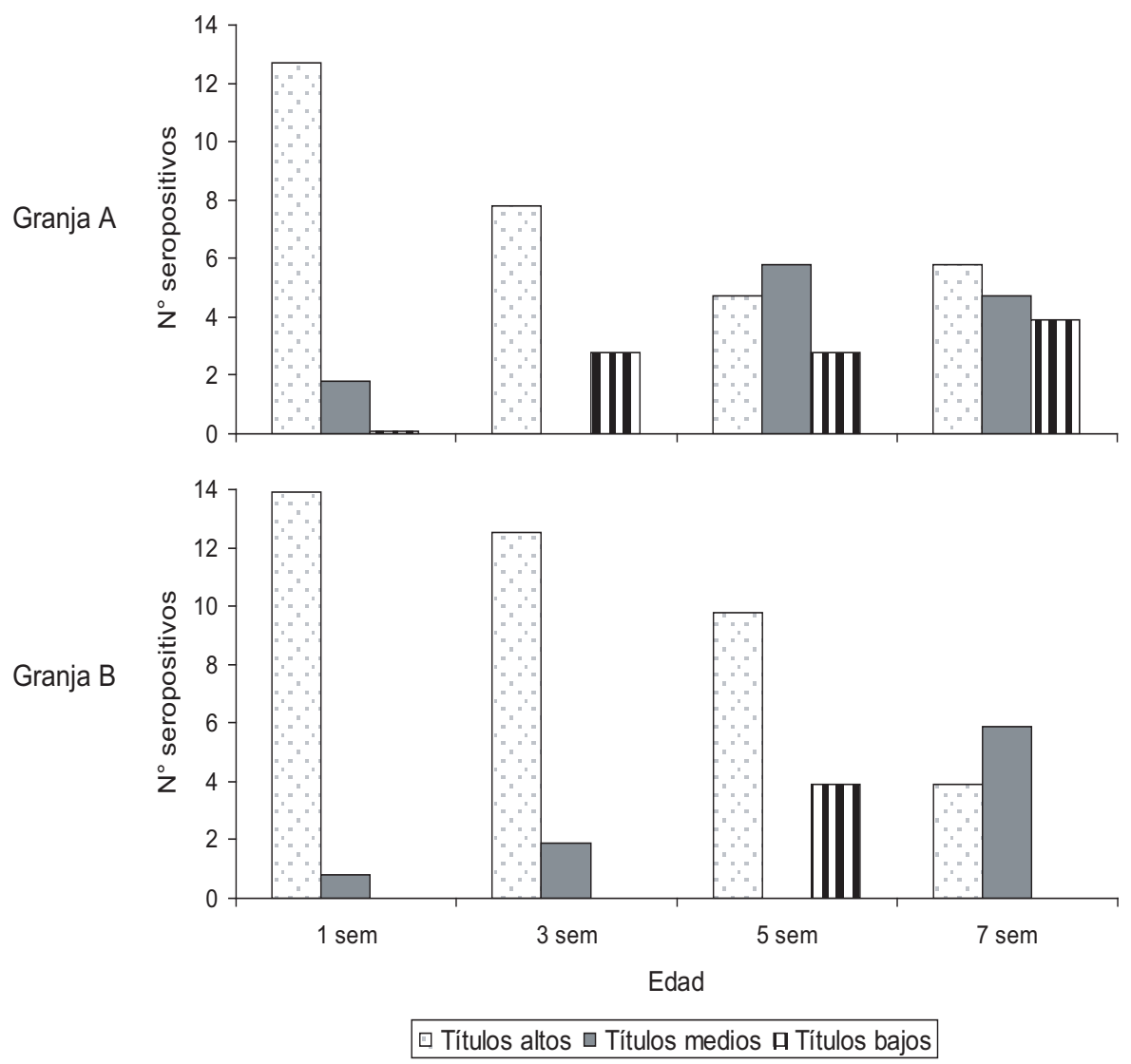

Figura 1. Número de lechones según edad y título de anticuerpos pasivos contra el virus de Peste Porcina Clásica en dos granjas porcinas de Lima con diferente estrategia de vacunación

engorde, con vacunación contra la PPC entre los 18 a 21 días postparto (granja B).

El número de lechones muestreado fue determinado según el criterio de Stevenson (1999), quien menciona que en una población de 300 o más cerdos, con un $95 \%$ de confianza y $5 \%$ de error, el número mínimo de animales a muestrear es de 5 , debido a que más del 50\% de los animales presentará anticuerpos vacunales contra el vPPC. Se colectó muestras de sangre de 15 lechones por granja a la $1^{\mathrm{a}}, 3^{\mathrm{a}}, 5^{\mathrm{a}}$ y $7^{\mathrm{a}}$ semana de edad y muestras de sangre de 15 marranas por granja por única vez y al inicio del estudio.
La detección de anticuerpos contra el vPPC fue mediante un ELISA de bloqueo (Bommeli Diagnostic - IDEXX, USA) y según el protocolo descrito en el manual del kit. De modo arbitrario, los resultados fueron agrupados, de acuerdo al porcentaje de inhibición, como títulos altos $(>80)$, medios (60$80)$ y bajos (40-60).

La diferencia entre los niveles de anticuerpos en los lechones de las dos granjas se estableció mediante la prueba de "t" de Student para muestras independientes (González y Falcón, 1999). La existencia de asociación entre la seropositividad y la granja de procedencia se midió con la prueba de Chi Cuadrado. 


\section{Resultados}

E1 92.5\%(111/120) de los lechones presentaron anticuerpos pasivos contra el vPPC, no encontrándose diferencia significativa entre granjas. Asimismo, todos los lechones (30/ 30) de ambas granjas fueron seropositivos en la primera semana de edad (Cuadro 1).

En el Cuadro 2 se presenta los promedios de los niveles de anticuerpos pasivos contra el vPPC, observándose una diferencia estadística $(p<0.05)$ en la primera y tercera semana de edad entre granjas. Se observa, además, que el coeficiente de variación de los niveles de anticuerpos por semana fue mayor en la granja $\mathrm{A}$.

En la Fig. 1 se presenta la distribución de lechones con anticuerpos pasivos contra el vPPC con títulos altos, medios y bajos, observándose que los lechones de la granja $\mathrm{B}$ presentaron una mayor homogeneidad en el descenso del número de animales con títulos de anticuerpos altos comparado con la granja $\mathrm{A}$.

E1 93.3\% (28/30) de las marranas presentaron anticuerpos contra el vPPC, siendo la excepción dos marranas de la granja B. El promedio de los niveles de anticuerpos en las marranas de la granja A fue de 89.2 y en la granja B de $84.9 \%$, no observándose diferencia significativa.

\section{Discusión}

La presencia de anticuerpos pasivos contra el vPPC en el total de lechones a la primera semana de edad indica una adecuada transferencia de anticuerpos calostrales en las dos granjas (Cuadro 1). No obstante, si bien la transferencia de anticuerpos fue efectiva, no solo depende de la estrategia de vacunación sino, además, del consumo de calostro por el lechón en el momento oportuno. Por otro lado, la presencia de lechones sin o con bajo nivel de anticuerpos a partir de la segunda semana en la granja A y tercera semana en la granja B (Cuadro 2) podría indicar la presencia de anticuerpos pero que no fueron detectados a pesar de la alta sensibilidad de la prueba utilizada (99\%) o que la ingestión de calostro fue inadecuada, ya sea en cantidad o en tiempo, ya que las marranas de las dos granjas tuvieron niveles altos de anticuerpos contra el vPPC. Otra posibilidad es la existencia de lechones con infección persistente pues en estos animales los anticuerpos pasivos son agotados tempranamente en un intento de remover al virus del torrente sanguíneo (Stevenson, 1999).

Rivera et al. (1999) encontraron en algunas granjas tecnificadas del valle de Lima con programas de vacunación contra la PPC, un $20 \%$ de lechones de 1 a 20 días de edad con pobre condición física, que eran positivos a antígeno viral, demostrando la presencia de infecciones pre y post natales con cepas del VPPC, posiblemente de baja virulencia, así como deficiencias en el manejo sanitario de la granja, lo que sumado a la continua presencia de poblaciones susceptibles favorecerían la persistencia de cepas de baja virulencia .

La falta de uniformidad en el agotamiento de los anticuerpos pasivos en los lechones de la granja A, sugiere un manejo sanitario deficiente, ya que los lechones son destetados y reagrupados a las tres semanas de edad, ocasionándoles una inmunodepresión transitoria (Mc Cauley y Hartmann, 1984), lo cual podría ser aprovechado por el VPPC para infectar animales susceptibles y persistir en la granja.

No se pudo determinar el momento ideal para la vacunación contra la PPC con relación a la disminución de los anticuerpos maternales pues los lechones fueron vacunados al finalizar la séptima semana ( \pm 50 días de edad) de acuerdo al programa de vacunación contra la PPC de ambas granjas. Existen reportes que los anticuerpos pasivos disminuyen en forma gradual y que podrían persistir por más de tres semanas (Corthier y 
Charley, 1977, Launais et al., 1978) e inclusive hasta la décima semana de edad (Vandeputte et al., 2001).

El tiempo de persistencia de estos anticuerpos, sin duda, estará en relación a la inmunidad de la marrana y a la cantidad de inmunoglobulinas ingeridos por el lechón. Los grupos de lechones que tuvieron bajos títulos de anticuerpos en primera semana de edad, posiblemente tendrían una adecuada respuesta inmunitaria post vacunal pero los grupos que tuvieron altos o medianos títulos de anticuerpos la respuesta post vacunal podría no ser óptima porque los anticuerpos pasivos interfieren con la replicación del virus vacunal (Fig. 1) ocasionando una pobre y lenta respuesta inmunitaria temporal en el animal vacunado (Aynaud y Launais, 1978).

El perfil serológico de las marranas de la granjas A $(89.22 \%)$ y B ( $84.93 \%)$ vacunados contra el VPPC fueron similares pero el pasaje de anticuerpos pasivos a los lechones fue más uniforme en la granja B; sin embargo, en esta granja se detectaron dos marranas seronegativas a pesar de haber sido vacunadas y no tuvieron vPPC, descartándose que fueran marranas portadoras. La existencia de marranas seronegativas a pesar de haber sido vacunadas es intrigante, sobre todo en granjas donde al parecer, tienen un buen sistema de manejo y bioseguridad, aunque también es posible que durante el muestreo estuvieran inmunosuprimidas o que desarrollaron tolerancia al antígeno vacunal.

Existen animales que no generan anticuerpos contra el VPPC post vacunación, y podrían ser los responsables de la persistencia del virus en la granja por su alta susceptibilidad a la infección viral (Camargo et al., 2002). Los resultados del estudio sugieren que cada granja debe tener un sistema de monitoreo serológico para detectar a los animales sin anticuerpos post vacunación a fin de determinar el tiempo de agotamiento de los anticuerpos pasivos para establecer un adecuado programa de vacunación contra la PPC.

\section{Conclusiones}

- Los anticuerpos pasivos en lechones, nacidos de marranas vacunadas, fueron detectados aún en la séptima semana de edad.

- Los niveles de los anticuerpos pasivos en los lechones influyen sobre la estrategia de vacunación contra la peste porcina clásica.

- Las marranas tuvieron altos títulos anticuerpos contra el vPPC sin afectarse por la estrategia de vacunación.

\section{Agradecimientos}

Los autores agradecen al Dr. Cesar Gavidia Chucán por su valioso apoyo en la interpretación estadística.

\section{Literatura Citada}

1. Aynaud JM, Launais M. 1978. Hog cholera: immunization of young pigs with thiverval strain vaccine in the presence of calostral immunity. Dev Biol Stand 41: 381-387.

2. Camargo I, Rivera H, Benito A. 2002. Detección de animales portadores del virus de la Peste Porcina Clásica en una granja tecnificada del valle de Lima. Rev Inv Vet, Perú 13(1): 56-60.

3. Corthier G, Charley B. 1977. Influence of colostral antibodies on pig immunization against hog cholera virus. Ann Rech Vet 9: 245-254.

4. Choi C, Chae C. 2003. Detection of classical swine fever virus in the ovaries of experimentally infected sows. J Comp Path 128: 60-66.

5. Fauquet CM, Mayo MA, Maniloff J, Desselberger $U$, Ball LA. 2005. Virus taxonomy. Eighth Report of the International Committee on Taxonomy of Viruses. San Diego, USA: Academic Press. 1259 p. 
6. González A, Falcón N. 1999. Análisis de datos en Medicina Veterinaria. Pub.Tec. FMV. UNMSM N. ${ }^{\circ} 41$ : 18-22.

7. Launais M, Aynaud JM, Corthier G 1978. Hog cholera virus: Active immunization of piglets with Thiverval strain in the presence and absence of colostral passive immunity. Vet Microbiol 3:31-43.

8. Mc Cauley I, Hartmann PE. 1984. Changes in pig leucocytes, lymphocytes $\mathrm{B}$ and plasma cortical from birth to 3 weeks after weaning. Res Vet Sci 37: 234-241

9. Moennig V. 2000. Introduction to classical swine fever virus, disease and control policy. Vet Microbiol 73: 93-102.

10. Moennig V, Floegel-Niesmann G, Greiser-Wilke I. 2003. Clinical signs and epidemiology of classical swine fever: A review of new knowledge. Vet J 165: 11-20.

11. [OIE] Organización Mundial de Sanidad Animal. 2004. Ficha técnica de enfermedades. Peste porcina clásica. [Internet], [7 julio 2006]. Disponible en: www.oie.int/eng/maladies/fiches/ A_A130.htm

12. Rivera H. 1994. Peste porcina clásica: Una revisión. Rev Pec Inv IVITA 7(2): 75-82.
13. Rivera H, Angeles R, Sandoval N, Manchego A. 1999. Persistencia del virus de Peste Porcina Clásica de baja virulencia en el sistema nervioso central de lechones de granjas tecnificadas. Rev Inv Vet, Perú 10(1): 1-10.

14. Stevenson GW. 1999. Common mistakes in interpretation of population serology. USA: Proc Am Assoc Swine Pract.

15. Vandeputte J, Too HL, Fook K, Chen C, Chai KK, Lia GA. 2001. Adsorption of colostral antibodies against classical swine fever, persistence of maternal antibodies, and effect on response to vaccination in baby pigs. Am J Vet Res 62: 1805-1811.

16. Van Oirschot JT, Terpstra CA. 1977. A congenital persistent swine fever infection. I. Clinical and virological observations II. Immune response to swine fever virus and unrelated antigens. Vet Microbiol 2: 121-142.

17. Van Oirschot JT. 1999. Diva vaccines that reduce virus transmission. J Biotechnol 73: 195-205.

18. Van Oirschot JT. 2003. Vaccinology of classical swine fever: from lab to field. Vet Microbiol 96: 367-384. 